\title{
Stakeholders' perceptions on performance of the Livestock Disease Surveillance system in Uganda: A case of Pallisa and Kumi Districts
}

\author{
Josephine Namayanja ${ }^{1}$, Michel Dione $^{2}$ and Joseph M. Kungu ${ }^{3^{*}}$ (1)
}

\begin{abstract}
A reliable livestock disease surveillance system should detect changes in health events whenever they occur. Such a system ought to be evaluated regularly to ensure it provides valuable information in an efficient manner. Thus, a cross-sectional study was carried out in 2017 to assess eight attributes of the livestock disease surveillance systems in Pallisa and Kumi districts, Uganda. A total of 772 livestock farmers were interviewed to evaluate the surveillance system at their level, using a structured questionnaire. Guided interviews were also carried out with 13 key informants who included all veterinary staff at the districts and sub-county administrative units, as well as two officials at the Ministry of Agriculture Animal Industry and Fisheries (MAAIF).

The stakeholders interviewed at the three different levels of the livestock diseases surveillance system perceived the system as useful, with ability to detect epidemics and initiate their control if they occurred. The surveillance system was perceived to be considerably representative, sensitive and acceptable, with the ability to generate data of good quality. However, key emerging issues that need improvement were noted. These included poor laboratory diagnostic services, inability to work within the means of available resources, slow data transmission and feedback, and nonspecific surveillance forms leading to poor quality of data collected.

Poor communication along the surveillance system chain and inadequate staffing were noted as the major challenges faced by the surveillance system in the two districts.

Although perceived to be functional, the livestock surveillance requires improvements for efficient disease detection and control. For better performance, the surveillance system could be strengthened by establishing and equipping laboratories for efficient confirmatory diagnosis of diseases; adjusting to work within the means of available resources; improving the reporting process through quick data transmission and quick feedback and designing precise surveillance form to improve quality of data collected.
\end{abstract}

Keywords: Livestock diseases surveillance, Disease reporting, Farmers, Uganda

\section{Background}

Livestock disease surveillance has been identified as playing an essential role in setting a platform for intervention strategies aimed at lowering incidence or completely eradicating infections (FAO 2011). The system involves an organized, systematic means of detecting, reporting, recording, analysing and disseminating data on the

\footnotetext{
* Correspondence: kungu@live.com; JKungu@covab.mak.ac.ug ${ }^{3}$ College of Veterinary Medicine, Animal Resources and Biosecurity Makerere University, P. O. Box 7062, Kampala, Uganda

Full list of author information is available at the end of the article
}

occurrence of disease based on evidence from the field (Thacker et al. 1983). An efficiently working livestock disease surveillance system has been described as very important in minimizing rapidly spreading diseases that cause heavy economic losses to farmers and suppress zoonotic diseases that could endanger human lives (Doherr and Audigé 2001; Hoinville et al. 2013). This results in improved livestock health, thereby enhancing access to local and international markets for animals and their products as well as public health protection (Mariner et al. 2011). An effective disease surveillance 
system helps empower decision-makers in Ministries of Agriculture and Finance, local governments and donor agencies, to best lead and manage the target resources and to evaluate animal health programmes (Mariner et al. 2011).

Various criteria have been used to describe livestock disease surveillance systems; they include the scope of surveillance, type, methods of data collection, dependence on control, epidemiological situation and population under surveillance activities (Calba et al. 2015).

Internationally, networks such as World Organization for Animal Health-World Animal Health Information Database (OIE-WAHID), Food and Agriculture OrganizationEmergency Prevention for Transboundary Animal and Plant Pests and Diseases (FAO-EMPRES-I), Animal Resources Information System-African Union-Interafrican Bureau of Animal Resources (ARIS-AUIBAR) and Global Early Warning and Response System (GLEWS) globally address the various animal surveillance needs. These networks provide for the exchange of information from local surveillance networks between partner countries (Vallat 2002).

There are also regional networks which play an important role in sharing animal disease information among the stakeholder states. An example is the Epidemiology and Informatics Subcommittee (EIS) of the Southern African Development Community (SADC) which has been essential in promoting measures that limit transboundary animal diseases' spread, thereby enhancing safe trade in livestock and livestock products (African UnionInterafrican Bureau for Animal R 2009).

At the national level in Uganda, the National Animal Diseases Diagnostics and Epidemiology Centre (NADDEC) was established to develop and strengthen a functional epidemiological surveillance system for all animal diseases in all districts through a systematic information collection and sharing. This has been done in collaboration with the training and research institutions, while overall management of the activities is by the Ministry of Agriculture Animal Industry and Fisheries (MAAIF) administration (Wanderema 2014).

Regular evaluation of livestock disease surveillance systems is vital in identifying the surveillance gaps, thereby efficiently guiding stakeholders on appropriate priority setting and allocation of resources. However, no standardized and consistent evaluation of the livestock disease surveillance system structure has been conducted in Uganda. The strength and limitations of the information output of the existing national surveillance system are unknown. Therefore, this study evaluated the livestock disease surveillance system in Kumi and Pallisa districts with regard to its ability to detect livestock diseases early and accurately as well as induce control.

\section{Study area}

A cross-sectional study was conducted between April and July 2017 to evaluate the performance of the livestock disease surveillance system in Kumi and Pallisa districts. The two districts are located in eastern Uganda and are agro-pastoral communities which have always experienced outbreaks of key notifiable diseases including foot and mouth disease (FMD), contagious bovine pleuro pneumonia (CBPP), lumpy skin disease (LSD), African swine fever (ASF), Newcastle disease (NCD) and rabies (Wanderema 2014). The livestock disease surveillance system was also assessed at MAAIF headquarters and NADDEC in Entebbe.

\section{Methodology}

\section{Study design}

The selected study sites were part of the five most recently FMD-affected districts in Uganda by the time this study was conducted. These included Soroti, Kumi, Bukedea, Mbale and Pallisa districts (MAAIF 2017). Pallisa and Kumi districts were then selected by simple random sampling using Microsoft Excel. One FMD worst hit sub-county in each of the districts was purposively selected based on the guidance from the District Veterinary Officers. Nyero Sub-County in Kumi and Puti-puti Sub-County in Pallisa were selected. For descriptive purposes, the stakeholders of the livestock surveillance system evaluated were categorized into three, namely bottom-level actors (livestock farmers), mid-level (sub-county and district veterinary staff) and the top level (Assistant Commissioner of the Department of Veterinary Diagnostics and Epidemiology Division and the Commissioner of Animal Health, MAAIF). A schematic description of the disease surveillance system assessed in this study is given in Fig. 1.

\section{Sample size determination for farmer respondents}

The sample size for farmer respondents was calculated considering an infinite population (no recent census data) using the formula adopted from Thrusfield (1995) as follows:

$$
n=\left[Z^{2} P(1-P)\right] / d^{2}
$$

where $n$ was the required sample size; $Z$ the multiplier from normal distribution (1.96) at a probability level of $0.05 ; P$ the estimated response distribution which was set at $50 \%$, considering that there was no reliable data on the number of livestock keepers in Nyero and Puti-puti sub-counties; and $d$ was the desired margin of error (0.05) with a 95\% level of confidence. The minimum sample size was calculated to be 384 livestock keeping households in each sub-county in Kumi and Pallisa districts. 


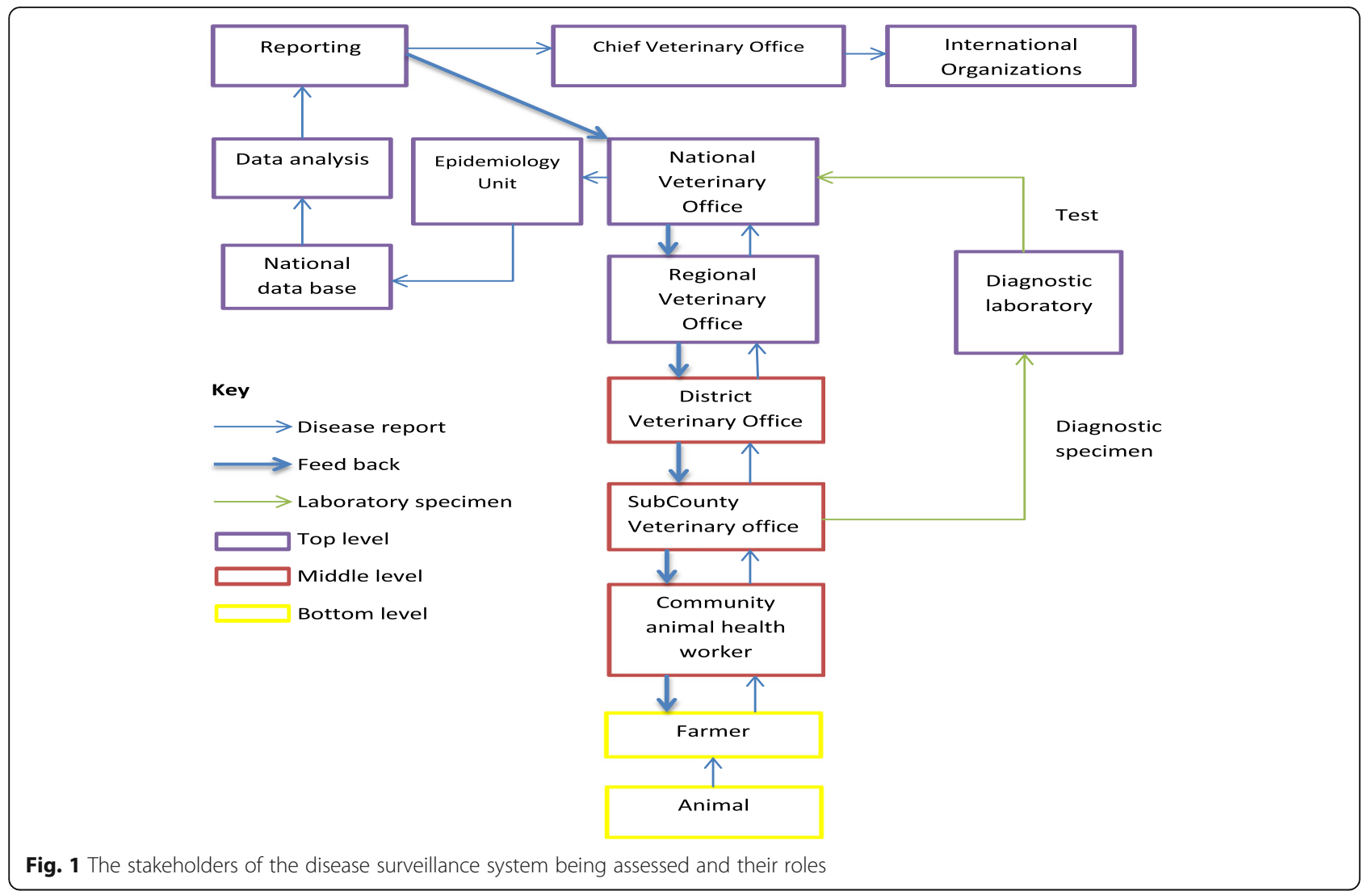

The target population was all livestock farming households in Nyero and Puti-puti sub-counties of Kumi and Pallisa districts respectively; the sampling frame was a list of all livestock (including pigs, goats, sheep, cattle and poultry) farming households in Nyero Sub-county in Kumi District and Puti-puti Sub-County in Pallisa District, provided by local sub-county veterinary staff. The respective sample sizes of respondents were drawn from the list of farming households in each Sub-County by simple random sampling using Microsoft Excel.

\section{Data collection and analysis}

The livestock disease surveillance system was assessed and data collected from farmers, district veterinary staffs and MAAIF officials based on the attributes by Center for Disease Control (CDC) and Thacker et al. (CDC 2001; Thacker et al. 1983), with modifications as follows:

Usefulness: The livestock disease surveillance system was considered to be useful if it contributed to the prevention and control of adverse health-related events, including an improved understanding of the animal health implications of such events which is reflected by documented changes in policies and procedures as a result of the information generated by the system.
Simplicity: Referred to both its structure and ease of operation. The stakeholders were interviewed about the flow of information and the process of reporting.

Flexibility: A good livestock disease surveillance system is the one which can adapt to changing information needs or operating conditions with little additional time, personnel or allocated funds. The ease of introducing new components in the reporting system was assessed.

Data quality:Rreflects the completeness and validity of the data recorded in the livestock disease surveillance system. The study measured the completeness of the received reports compared to expected reports, and the percentage of field forms/reports and the level of their analysis.

Acceptability: Reflects the willingness of persons and organizations to participate in the surveillance system. An objective measure of willingness to participate in the reporting was assessed based on the reports' submission rates by the DVO offices of the two districts.

Sensitivity: The livestock disease surveillance system was considered at two levels; namely at the level of case reporting, sensitivity referred to the proportion of cases of a disease (or other health-related events) detected by the system. Secondly, sensitivity can refer to the ability to detect outbreaks, including the ability to monitor changes in the number of cases over time. Scores were 
made based on the number of confirmed cases by laboratory diagnosis compared to a gold standard positive result.

Representativeness: A functional livestock disease surveillance system that is representative accurately describes the occurrence of a health-related event over time and its distribution in the population by place and animal or herd. This was assessed by comparing the characteristics of reporting events to the expected occurrence of the events based on the epidemiological knowledge.

Timeliness: Refers to the speed between steps in the livestock disease surveillance system.

The data collected from farmers in the two districts was entered in Microsoft Excel sheets for cleaning and responses of farmers to the key questions of the three attributes summarized as frequencies. In each livestockkeeping household, a structured questionnaire was administered to the household head or an adult resident (18 years and above) family member, to assess three key livestock surveillance system attributes, namely usefulness, simplicity and timeliness which were relevant at the farmer level.

Data from key informants (district veterinary staff and two officials from MAAIF) was qualitatively analysed in themes (eight attributes) and sub-themes (strengths and weaknesses) as described by Maguire and Delahunt (2017).

Guided key informant interviews using a question checklist were conducted with all local veterinary staff of the two districts. The checklist assessed all the eight livestock disease surveillance attributes. The guided key informant interviews were also conducted with the Assistant Commissioner of the Department of Veterinary Diagnostics and Epidemiology Division and the Commissioner of Animal Health, MAAIF.

\section{Results}

Socio-demographic characteristics of farmer respondents A total of 772 respondents were interviewed from the two districts; $74 \%$ of these were above 30 years of age. In most of the respondents, $82 \%$ were males. Sixty-two percent of the respondents had attained only primary level of formal education (Table 1).

\section{Type of livestock kept by farmers in Pallisa and Kumi}

\section{districts}

The majority of the farmers, $85.8 \%$, kept cattle, $79.9 \%$ kept goats and sheep and $52.5 \%$ kept poultry, while only $30.4 \%$ kept pigs (Table 2).

The livestock disease surveillance system attributes at the farmer level

\section{Usefulness of farmer disease reporting}

The evaluation indicated that the farmers were involved in the reporting of key disease outbreaks. They were able
Table 1 The socio-demographic characteristics of farmer respondents

\begin{tabular}{llll}
\hline Variable & $\begin{array}{l}\text { Pallisa } \\
\text { (frequency) }\end{array}$ & $\begin{array}{l}\text { Kumi } \\
\text { (frequency) }\end{array}$ & $\begin{array}{l}\text { Overall } \\
\text { frequency (\%) }\end{array}$ \\
\hline $\begin{array}{l}\text { Age group (years) } \\
18-30\end{array}$ & 146 & 54 & $200(25.9)$ \\
$>30$ & 239 & 333 & $572(74.1)$ \\
Sex & 331 & 305 & $636(82.4)$ \\
$\quad$ Male & 54 & 82 & $136(17.6)$ \\
Female & 31 & 13 & $44(5.7)$ \\
Formal education & 231 & 251 & $482(62.4)$ \\
$\quad$ None & 100 & 81 & $181(23.5)$ \\
Primary & 23 & 42 & $65(8.4)$ \\
$\quad$ Secondary & & & $387(50.1)$ \\
$\quad$ Tertiary & & 182 & $385(49.9)$ \\
Occupation & 204 & 205 & \\
$\quad$ Farmer & 181 & &
\end{tabular}

to describe the clinical manifestation of the five common livestock disease outbreaks (FMD, CBPP, ASF, PPR, HPAI) in the two districts. The farmers noted that their role in early detection and reporting of disease outbreaks was important in control and prevention of the spread of such conditions in livestock. There was a general agreement among the farmers interviewed that quarantine measures to limit livestock movements and ban the trade of livestock were only instituted following reports to the veterinary authorities at the Sub-County. Citing a recent FMD outbreak example, the farmers noted that following their report to the Veterinary Officers at the

Table 2 Frequencies of types of livestock kept in Pallisa and Kumi districts

\begin{tabular}{|c|c|c|c|}
\hline Variable & $\begin{array}{l}\text { Pallisa (number } \\
\text { of respondents) }\end{array}$ & $\begin{array}{l}\text { Kumi (number } \\
\text { of respondents) }\end{array}$ & $\begin{array}{l}\text { Overall } \\
\text { frequency (\%) }\end{array}$ \\
\hline \multicolumn{4}{|l|}{ Cattle } \\
\hline Yes & 301 & 361 & $662(85.8)$ \\
\hline No & 84 & 26 & $110(14.2)$ \\
\hline \multicolumn{4}{|c|}{ Goats and sheep } \\
\hline Yes & 254 & 363 & 617 (79.9) \\
\hline No & 131 & 24 & $155(19.1)$ \\
\hline \multicolumn{4}{|l|}{ Pigs } \\
\hline Yes & 23 & 212 & $235(30.4)$ \\
\hline No & 362 & 175 & 537 (69.6) \\
\hline \multicolumn{4}{|l|}{ Poultry } \\
\hline Yes & 123 & 282 & $405(52.5)$ \\
\hline No & 262 & 105 & 367 (7.5) \\
\hline
\end{tabular}


Sub-County, quarantine was declared followed by government-supported vaccination campaigns in these outbreak areas.

\section{Simplicity of farmer disease reporting}

Farmers' responses indicated that visits to the veterinary staff office were the most common method of reporting occurrence of disease outbreaks. This often led to the institution of interventions by the veterinarians.

\section{Timeliness to farmer disease reporting}

Most of the farmers (78\%) indicated that whenever they reported the occurrence of an outbreak, they were able to receive a response from the technical staff within 1 day.

Table 3 shows the summary of responses to key questions used to assess the attributes at the farmer level.
The livestock disease surveillance system at the District Veterinary staff level

All the 13 veterinary staff of Pallisa (7) and Kumi (6) districts were interviewed and their expert opinion responses regarding the attributes assessed for relationships and trends are summarized in Table 4.

The veterinary staff were also asked to rank the factors that affect performance of the livestock disease surveillance system. Poor remuneration of technical staff, poor communication along the surveillance system chain and inadequate staffing were identified as the major challenges.

The livestock disease surveillance system at the MAAIF level The opinion of the Assistant Commissioner of the Department of Veterinary Diagnostics and Epidemiology Division and the Commissioner of Animal Health, MAAIF, regarding the livestock disease surveillance was sought. Table 5 summarizes the key findings of the perceptions of the two top officials.

Table 3 A summary of responses to key questions used to assess usefulness, simplicity and timeliness at the farmer level

\begin{tabular}{|c|c|c|c|}
\hline Variable & $\begin{array}{l}\text { Pallisa (frequency } \\
\text { of respondents) }\end{array}$ & $\begin{array}{l}\text { Kumi (frequency } \\
\text { of respondents) }\end{array}$ & $\begin{array}{l}\text { Overall frequency of } \\
\text { respondents (\%) }\end{array}$ \\
\hline \multicolumn{4}{|l|}{ Report disease outbreaks } \\
\hline Yes & 380 & 371 & $751(97.3)$ \\
\hline No & 5 & 16 & $21(2.7)$ \\
\hline \multicolumn{4}{|l|}{ Where disease outbreaks are reported } \\
\hline Community leader & 19 & 10 & $29(3.8)$ \\
\hline Sub-County Veterinary Officer & 281 & 325 & $590(78.5)$ \\
\hline DVO & 85 & 52 & $133(17.7)$ \\
\hline \multicolumn{4}{|l|}{ Interventions used } \\
\hline Quarantine & 193 & 252 & $433(57.6)$ \\
\hline Vaccination & 98 & 108 & $201(26.7)$ \\
\hline Treatment & 94 & 27 & $118(15.7)$ \\
\hline \multicolumn{4}{|l|}{ Whether interventions are effective } \\
\hline Yes & 300 & 321 & $222(29.6)$ \\
\hline No & 85 & 66 & $529(70.4)$ \\
\hline \multicolumn{4}{|l|}{ Methods used to report outbreaks } \\
\hline Visit veterinary office & 212 & 317 & $529(68.5)$ \\
\hline Other (telephone veterinary office, send a letter) & 173 & 70 & $243(31.5)$ \\
\hline \multicolumn{4}{|l|}{ Feedback after reporting } \\
\hline No feedback & 23 & 43 & $66(8.5)$ \\
\hline Visited by technical people & 362 & 344 & $706(91.5)$ \\
\hline \multicolumn{4}{|c|}{ Average time interval between reporting and intervention } \\
\hline 1 day (12 or $24 h)$ & 316 & 287 & $603(78.1)$ \\
\hline 1 week (7 days) & 65 & 100 & $165(21.4)$ \\
\hline 1 month (30 days) & 4 & 0 & $4(0.5)$ \\
\hline \multicolumn{4}{|l|}{ Measures to improve reporting and timely intervention } \\
\hline Form farmers taskforce & 54 & 49 & $103(13.3)$ \\
\hline Sensitize farmers & 21 & 38 & $59(7.6)$ \\
\hline Form farmers task force and sensitize farmers & 310 & 300 & $610(79.1)$ \\
\hline
\end{tabular}


Table 4 A summary of the mid-level livestock surveillance system evaluation

\begin{tabular}{|c|c|c|}
\hline Theme & Sub-theme: strengths & Sub-theme: weakness/areas for improvement \\
\hline Usefulness & $\begin{array}{l}\text { Detects trends signalling changes in disease } \\
\text { occurrence } \\
\text { Detects epidemics } \\
\text { Provides estimates of morbidity and mortality } \\
\text { magnitude of disease } \\
\text { Leads to improved clinical practice } \\
\text { Triggers intervention by MAAIF }\end{array}$ & $\begin{array}{l}\text { Identification of risk factors associated with } \\
\text { disease occurrence } \\
\text { Assessment of effects of disease control } \\
\text { measures }\end{array}$ \\
\hline Simplicity & $\begin{array}{l}\text { Visits to the veterinary office and use of } \\
\text { telephones by farmers to report suspected cases }\end{array}$ & $\begin{array}{l}\text { Incompetence of farmers to identify emerging } \\
\text { diseases } \\
\text { Inadequate information for disease diagnosis } \\
\text { Reluctance of DVOs to submit monthly reports } \\
\text { to MAAIF }\end{array}$ \\
\hline Timeliness & $\begin{array}{l}\text { Farmers quickly report suspected diseases to } \\
\text { the veterinary staffs }\end{array}$ & $\begin{array}{l}\text { Delayed intervention } \\
\text { Inadequate financial support from MAAIF to } \\
\text { facilitate the surveillance activities }\end{array}$ \\
\hline Representativeness & $\begin{array}{l}\text { Generic description of the distribution of } \\
\text { infection in the population by place and } \\
\text { type of animal hosts possible using information } \\
\text { reported by farmers }\end{array}$ & $\begin{array}{l}\text { More accurate information describing the } \\
\text { pattern of the outbreak in the community like } \\
\text { herd size, management systems and exact onset } \\
\text { of infection left out since this requires technical } \\
\text { expertise }\end{array}$ \\
\hline Sensitivity & $\begin{array}{l}\text { Case reporting when seeking treatment for sick } \\
\text { animals is high, hence the ability to detect } \\
\text { disease outbreaks }\end{array}$ & $\begin{array}{l}\text { Diagnosis is only based on clinical signs } \\
\text { Laboratory confirmatory diagnosis not done }\end{array}$ \\
\hline Flexibility & None & $\begin{array}{l}\text { Active functioning of the system is inclined to funding from } \\
\text { international projects. } \\
\text { The system is not able to adjust to variations } \\
\text { in funds and personnel }\end{array}$ \\
\hline Acceptability & $\begin{array}{l}\text { The farmers always show willingness to report } \\
\text { diseases when they occur }\end{array}$ & $\begin{array}{l}\text { Need for all actors to improve on their } \\
\text { involvement in the reporting, transmitting and } \\
\text { providing of feedback }\end{array}$ \\
\hline Data quality & $\begin{array}{l}\text { Case information obtained from the local } \\
\text { communities is validated by local veterinarians } \\
\text { under instruction of the District Veterinary } \\
\text { Officer to avoid false alarms }\end{array}$ & $\begin{array}{l}\text { The surveillance forms provided by MAAIF need } \\
\text { to be revised to improve the quality of data } \\
\text { collected routinely }\end{array}$ \\
\hline
\end{tabular}

According to the two top-level actors, the performance of the livestock surveillance system is hindered by limited funds to facilitate the surveillance activities, inadequate staffing and laxity by district veterinary staff to participate in disease reporting.

\section{Discussion}

A properly functioning livestock disease surveillance system is crucial in detection and control of diseases. This compelled the undertaking an evaluation of the existing livestock disease surveillance in Uganda following set

Table 5 A summary of the top-level livestock surveillance system evaluation

\begin{tabular}{|c|c|c|}
\hline Theme & Sub-theme: strengths & Sub-theme: weakness/areas for improvement \\
\hline Usefulness and sensitivity & $\begin{array}{l}\text { Agreed that the system generates information } \\
\text { used in justification for lobby for funds for } \\
\text { disease control }\end{array}$ & $\begin{array}{l}\text { The effectiveness of disease control measures } \\
\text { not evaluated }\end{array}$ \\
\hline Simplicity and timeliness & $\begin{array}{l}\text { Information on severe outbreaks quickly } \\
\text { disseminated to MAAIF }\end{array}$ & $\begin{array}{l}\text { DVOs reluctant to submit monthly reports to } \\
\text { MAAIF regarding routine disease situation. } \\
\text { Incentives would be proposed for the best } \\
\text { performers to encourage consistent reporting } \\
\text { Electronic reporting could also ease the } \\
\text { reporting process }\end{array}$ \\
\hline Representativeness & $\begin{array}{l}\text { Generic description of the distribution of } \\
\text { infection in the population by place and type } \\
\text { of animal hosts possible using information } \\
\text { reported by farmers }\end{array}$ & $\begin{array}{l}\text { More accurate information describing pattern of } \\
\text { the outbreak in the community like herd size, } \\
\text { management systems and exact onset of infection } \\
\text { left out since this requires technical expertise }\end{array}$ \\
\hline $\begin{array}{l}\text { Flexibility, acceptability and } \\
\text { data quality }\end{array}$ & None & $\begin{array}{l}\text { The system is not able to adjust to variations in } \\
\text { funds and personnel. Data quality can be } \\
\text { improved by revising the existing surveillance data } \\
\text { form and also developing an electronic version } \\
\text { of this form }\end{array}$ \\
\hline
\end{tabular}


guidelines by CDC and Thacker et al. (CDC 2001; Thacker et al. 1983).

The stakeholders interviewed at the three different levels of the livestock diseases surveillance system perceived that the system was useful, with the ability to detect epidemics and induce their control if they occurred. This was in agreement with previous findings that farmers show high vigilance in reporting the outbreaks of known notifiable conditions (Cameron 2012). Notifiable diseases such as FMD, ASF and PPR are already known for devastating economic effects which result in panic among farmers in the affected communities, imploring them to report when morbidity increases.

This study showed that farmer livestock disease reporting system was simple but could not provide enough information to establish a confirmatory diagnosis. A study by Roeder et al. (1999) concurs that farmers are the primary source of information on disease outbreaks for livestock surveillance systems in developing countries like Uganda but is only enough to establish tentative diagnosis and not confirmation of disease presence.

This would require that stakeholders at each step of the system actively play their role (Hadorn and Stärk 2008).

Although the study revealed that the surveillance system was to a considerable extent representative, sensitive and acceptable and could generate data of good quality, key emerging issues that need improvement were noted. According to the study, the livestock surveillance system was not flexible in response to the fluctuating availability of resources. Like the other African countries, the Ugandan Livestock Disease Surveillance System faces serious challenges in its effective implementation due to human and financial resource inadequacies (Cameron 2012; FAO 2011).

A number of livestock disease surveillance options have been suggested by researchers over the last decades (Bruckner 2014; Calba et al. 2015; CDC 2001; Cirkel 2010; Thacker et al. 1983). However, the most appropriate surveillance system preferred by a country depends on existing surveillance needs, resources and challenges (FAO 2011). Therefore, this requires decision-makers (Directorate of Animal Resources) to identify the key constraints and setting up cheap yet effective surveillance approaches to meet Uganda's livestock disease surveillance needs in a timely manner.

Basing on the findings of this study, it has been observed that the key challenges, such as inadequate staffing in the districts, reluctance of DVOs to submit monthly livestock surveillance reports to MAAIF and inadequate funding of existing staff, have seriously stifled the current livestock disease surveillance system. The active surveillance component has also been affected by the tendency of NADDEC to rely on international projects for financial support, yet these are usually time-bound. This could have left the country's livestock disease surveillance needs still wanting - such as demonstration of freedom from diseases of global concern (rinderpest and avian influenza), early detection of incursions or outbreaks (avian influenza), case finding (endemic conditions like FMD), describing level of disease (endemic conditions) and detection of changes in disease distribution (Wanderema 2014).

\section{Conclusion}

This study showed that the existing livestock disease surveillance system in both Kumi and Pallisa districts was useful, simple and timely but requires improvements to make it beneficial for efficient disease detection and control. The study suggests that the performance of the livestock disease surveillance system could be strengthened by establishing and equipping laboratories for efficient confirmatory diagnosis of diseases; adjusting to work within the means of available resources; improving the reporting process through quick data transmission and quick feedback, and designing precise surveillance form to improve the quality of data collected.

\section{Abbreviations \\ ASF: African swine fever; FMD: Foot and mouth disease; HPAl: Highly pathogenic avian influenza; MAAIF: Ministry of Agriculture Animal Industry and Fisheries; NADDEC: National Animal Diseases Diagnostic and Epidemiology Centre; PPR: Pestes Petit Ruminantes}

\section{Acknowledgements \\ We acknowledge Bosco Okuyo, Mwebe, Esther Nambo, Patrick Emudong, Sam Lajja and Peter Muyimba, for the assistance rendered during data collection. We thank the farmers, veterinary staff of Pallisa and Kumi districts and MAAIF officials for accepting to participate in this study. We are also grateful to the PIs and staff of OHCEA country office for the timely release of logistics required during the study.}

\section{Authors' contributions}

JN and JMK designed and planned the study. JN, MD and JMK collected and analysed the data and drafted the manuscript. All authors edited and approved the final manuscript.

\section{Funding}

The work was funded by USAID-OHCEA.

\section{Availability of data and materials}

Data has been submitted to this journal as additional supporting file.

\section{Ethics approval and consent to participate}

The study was approved by the Research and Ethics Committee of the College of Veterinary Medicine Animal Resources and Biosecurity (COVAB) of Makerere University. Prior to participation in the study, the objectives of the research were explained to the respondents and formal consent obtained from the farmers by a signature or thumb print on the consent form while the District Veterinary staff and MAAIF staff orally consented. Research assistants with knowledge of English and the local languages (Ateso in Kumi and Lugwere in Pallisa) were used to interpret where participants did not understand English.

Consent for publication

Not applicable.

Competing interests

The authors declare that they have no competing interests. 


\section{Author details}

'Department of Livestock Health, Ministry of Agriculture, Animal Industry and Fisheries, Government of Uganda, Entebbe, Uganda. ${ }^{2}$ International Livestock Research Institute, c/o Bioversity International, P. O. Box 24384, Kampala, Uganda. ${ }^{3}$ College of Veterinary Medicine, Animal Resources and Biosecurity Makerere University, P. O. Box 7062, Kampala, Uganda.

Received: 5 February 2019 Accepted: 14 June 2019

Published online: 02 September 2019

\section{References}

African Union-Interafrican Bureau for Animal, R. 2009. Pan African Animal Health Yearbook 2009. Pan African Animal Health Yearbook, 2009, ix + $32+$ XIV pp.-ix $+32+$ XIV pp.

Bruckner, G.K. 2014. Systems of epidemiological control and surveillance of animal diseases at national and regionallevels. A report. Directorate of Animal Health, Private Bag X138, Pretoria 0001, South Africa report, pages 111-116.

Calba, C., F.L. Goutard, L. Hoinville, P. Hendrikx, A. Lindberg, C. Saegerman, and M. Peyre. 2015. Surveillance systems evaluation: a systematic review of the existing approaches. https://doi.org/10.1186/s12889-015-1791-5.

Cameron, A. 2012. Manual of basic animal disease surveillance. Nairobi: Interafrican Bureau for Animal Resources.

CDC. 2001. Updated guidelines for evaluating public health surveillance systems: Recommendations from the guidelines working group. MMWR Recommendations and Reports 50 (RR-13): 1-35 quiz CE1-E7.

Cirkel, M. 2010. Epidemiological surveillance systems. Veterinary Medicine Retrieved from http://www.fve.org/news/position_papers/miscellaneous/ epidemiological_surveillance_systems_K_Cirkel.pdf.

Doherr, M.G., and L. Audigé. 2001. Monitoring and surveillance for rare healthrelated events: A review from the veterinary perspective. Philosophical Transactions of the Royal Society of London Series B Biological Sciences 356 (1411): 1097-1106.

FAO. 2011. Challenges of animal health information systems and surveillance for animal diseases and zoonoses. In FAO animal production and health proceedings, 1-124.

Hadorn, D.C., and K.D.C. Stärk. 2008. Evaluation and optimization of surveillance systems for rare and emerging infectious diseases. Veterinary Research 39 (6): 1-12. https://doi.org/10.1051/vetres:2008033.

Hoinville, L.J., L. Alban, J.A. Drewe, J.C. Gibbens, L. Gustafson, B. Häsler, et al. 2013. Proposed terms and concepts for describing and evaluating animal-health surveillance systems. Preventive Veterinary Medicine 112(1-2): 1-12.

MAAIF (2017). The Republic of Uganda, Ministry of Agriculture Animal Industry and Fisheries monthly animal health reports.

Maguire, M., and B. Delahunt. 2017. Doing a thematic analysis: A practical, stepby-step guide for learning and teaching scholars. AISHE-J 8(3): 1-14.

Mariner, J., D. Pfeiffer, S. Costard, L. Knopf, J. Zingeser, D. Chibeu, et al. 2011. Surveillance for the present and the future. In Challenges of animal health information systems and surveillance for animal diseases and zoonoses, 15-19 FAO Animal Production and Health Proceedings.

Roeder, P. L., Masiga, W. N., Rossiter, P. B., Paskin, R. D., \& Obi, T. U. (1999). Dealing with animal disease emergencies in Africa:prevention and preparedness. Revue Scientifique et Technique (International Office of Epizootics), 18(1), 59-65.

Thacker, S.B., K. Choi, and P.S. Brachman. 1983. The surveillance of infectious diseases. JAMA: The Journal of the American Medical Association 249 (9): 1181-1185.

Thrusfield, M. 2007. Veterinary epidemiology. 3rd ed. Oxford: Blackwell Science

Vallat, B. 2002. Role of the international organisation for animal health (Office International des Epizooties: OIE) in the control of foot and mouth disease. Comparative Immunology, Microbiology and Infectious Diseases 25 (5-6): 383-392.

Wanderema, S.N.W. 2014. Factors associated with the low veterinary regulatory compliance in Uganda, their impact and quality management approaches to improve performance. A proceeding at Uganda Veterinary Association conference. Imperial hotel Kampala, Uganda.

\section{Publisher's Note}

Springer Nature remains neutral with regard to jurisdictional claims in published maps and institutional affiliations.

\section{Submit your manuscript to a SpringerOpen ${ }^{\circ}$ journal and benefit from:}

- Convenient online submission

- Rigorous peer review

- Open access: articles freely available online

- High visibility within the field

- Retaining the copyright to your article

Submit your next manuscript at $\boldsymbol{\nabla}$ springeropen.com 